\title{
Inhibition of protein tyrosine phosphatase non-receptor type 2 by PTP inhibitor XIX: Its role as a multiphosphatase inhibitor
}

\author{
Hien Thi Thu Le, Young-Chang Cho E Sayeon Cho ${ }^{*}$ \\ College of Pharmacy, Chung-Ang University, Seoul 06974, Korea
}

\begin{abstract}
Protein tyrosine phosphatases (PTPs) play crucial roles in signal transduction and their functional alteration has been detected in many diseases. PTP inhibitors have been developed as therapeutic drugs for diseases that are related to the activity of PTPs. In this study, PTP inhibitor XIX, an inhibitor of CD45 and PTEN, was investigated whether it inhibits other PTPs. Protein tyrosine phosphatase non-receptor type 2 (PTPN2) was selectively inhibited by the inhibitor in a competitive manner. Drug affinity responsive target stability (DARTS) analysis showed that the inhibitor induces conformational changes in PTPN2. Phosphorylation levels of signal transducer and activator of transcription 3 (STAT3) at Tyr-705, a crucial site for STAT3 activation and target site of PTPN2, decreased upon exposure to the inhibitor. Our results suggest that PTP inhibitor XIX might be considered as an effective regulator of PTPN2 for treating diseases related to PTPN2. [BMB Reports 2017; 50(6): 329-334]
\end{abstract}

\section{INTRODUCTION}

Protein tyrosine phosphorylation is a post-translational modification that leads to the regulation of many signal transduction pathways (1). Protein tyrosine phosphorylation is regulated by balanced action of protein tyrosine kinases (PTKs) and protein tyrosine phosphatases (PTPs) in mammalian cells (2). There are over 100 PTPs encoded in the human genome sharing a short active site 'signature motif' (3). Based on the amino acid sequences of their catalytic domains, PTPs are divided into four main families: (i) class I cysteine-based PTPs, (ii) class II cysteine-based PTPs: tyrosine-specific low molecular weight phosphatases, (iii) class III cysteine-based PTPs: Cdc25 phosphatase family, and (iv) aspartic acid-based

*Corresponding author. Tel: +82-2-820-5595; Fax: +82-2-8167338; E-mail: sycho@cau.ac.kr

https://doi.org/10.5483/BMBRep.2017.50.6.003

Received 5 January 2017, Revised 10 February 2017, Accepted 20 February 2017

Keywords: Drug affinity responsive target stability, Protein tyrosine phosphatase non-receptor type 2, PTP inhibitor XIX
PTPs $(3,4)$. Different members of the PTP families show individual specificities for suitable substrates in various signal transduction pathways (4).

Several studies have demonstrated that the regulation of the PTP activities might contribute to the therapeutic approach for the treatment of cancer, diabetes, and immunologic disorders (5). Discovery of the PTP inhibitors that selectively regulate PTP activity is a valuable way to treat various diseases $(6,7)$. In addition, studies for the specificity of PTP inhibitors on their target phosphatases will provide important information for the prediction of the effects of inhibitors in vivo (8).

PTP inhibitor XIX is a cell-permeable and stable synthetic analog of dephostatin (9). The chemical formula of PTP inhibitor XIX is N-[9, 10-dioxo-9, 10-dihydro-phenanthren-2-yl]2, 2-dimethyl-propionamide that has been reported as CD45 inhibitor (Fig. 1A) (10). CD45 is competitively inhibited by PTP inhibitor XIX, which leads to blockage of T-cell receptormediated proliferation for treatment of autoimmune disorders and organ graft rejection (9). In addition, PTP inhibitor XIX inhibits phosphatase and tensin homologue deleted on chromosome 10 (PTEN) which inhibits neutrophil function, reduces host defense in neutropenia-associated pneumonia, and is involved in type II diabetes $(11,12)$.

In this study, we screened additional PTPs to search for targets of PTP inhibitor XIX to evaluate its potential role as a multiphosphatase inhibitor. Protein tyrosine phosphatase non-receptor type 2 (PTPN2) was identified as a potent target of PTP inhibitor XIX. We also investigated the effect of PTP inhibitor XIX on PTPN2 conformation and the PTPN2regulated signaling pathway.

\section{RESULTS AND DISCUSSION}

Inhibitory effect of PTP inhibitor XIX on the PTPN2 activity Although PTP inhibitor XIX was reported as a PTEN or CD45 inhibitor that binds to the active site, its activity against other PTPs has not been investigated. Therefore, we investigated the effect of PTP inhibitor XIX on other PTPs by performing in vitro phosphatase assays to identify other potent target of PTP inhibitor XIX. Among ten PTPs tested, PTPN2 was selectively inhibited by PTP inhibitor XIX (Table 1). To further confirm that PTP inhibitor XIX inhibits PTPN2 activity, recombinant PTPN2 purified from bacteria was treated with various

ISSN: 1976-670X (electronic edition)

Copyright (c) 2017 by the The Korean Society for Biochemistry and Molecular Biology

(c) This is an open-access article distributed under the terms of the Creative Commons Attribution Non-Commercial License (http://creativecommons.org/licenses/by-nc/4.0) which permits unrestricted non-commercial use, distribution, and reproduction in any medium, provided the original work is properly cited. 
A

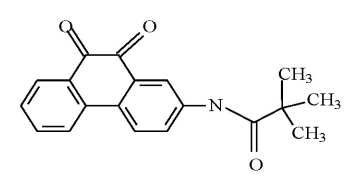

B

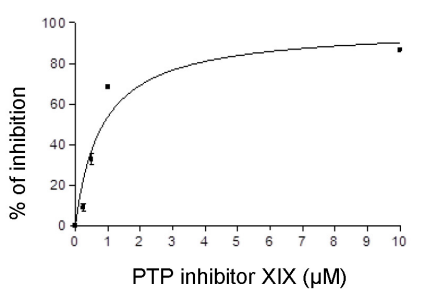

C

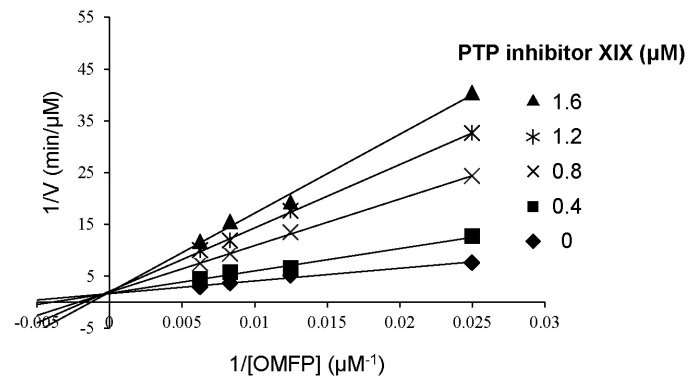

Fig. 1. Inhibitory effect of PTP inhibitor XIX on the PTPN2 activity by competitive inhibition. (A) Chemical structure of PTP inhibitor XIX is N-[9, 10-Dioxo-9, 10-dihydro-phenanthren-2-yl]-2, 2-dimethyl-propionamide. (B) PTPN2 was incubated with various concentrations of PTP inhibitor XIX $(0.4,0.8,1.2$, and $10 \mu \mathrm{M})$ at $37^{\circ} \mathrm{C}$ for $30 \mathrm{~min}$. Fluorescence emission from the product was measured. $\mathrm{IC}_{50}$ value of PTPN2 was calculated by Prism 3.0. (C) Kinetic analysis of PTPN2 inhibition by PTP inhibitor XIX (0.4, $0.8,1.2$, and $1.6 \mu \mathrm{M}$ ) was performed based on the theory of Lineweaver-Burk plots and the $\mathrm{K}_{\mathrm{i}}$ values were determined using the equation stated in materials and methods. Lineweaver-Burk plots of PTPN2 generated from reciprocal data.

concentrations of PTP inhibitor XIX. The inhibitor reduced PTPN2 activity in a dose-dependent manner with a half maximal inhibitory concentration $\left(\mathrm{IC}_{50}\right)$ of $0.95 \pm 0.05 \mu \mathrm{M}$ (Fig. 1B). In subsequent experiments, kinetic analyses based on the Michaelis-Menten equation were performed with PTP inhibitor XIX and PTPN2 to provide experimental evidence for the mechanism of inhibition. Lineweaver-Burk plots showed that $\mathrm{Ki}$ value of PTPN2 was $0.76 \pm 0.08 \mu \mathrm{M}$ (Fig. 1C). The results also indicated that PTP inhibitor XIX functions as a competitive inhibitor of PTPN2, suggesting that PTP inhibitor XIX suppresses the catalytic activity of PTPN2 by binding to its catalytic site.

Protective effect of PTP inhibitor XIX on PTPN2 proteolysis Next, we performed DARTS analysis to characterize whether binding of PTP inhibitor XIX to PTPN2 induced conformational change in PTPN2. DARTS is a recently developed method, which takes advantage of a reduction in the protease susceptibility of the target protein upon drug binding (13). PTPN2 was incubated with PTP inhibitor XIX or phenylmethylsulfonyl fluoride (PMSF), a trypsin inhibitor, prior to addition of trypsin (14). After additional incubation in the presence of trypsin, immunoblotting analysis was carried out to determine full-length PTPN2 levels. Proteolysis of PTPN2 processed by trypsin decreased in the presence of PTP inhibitor XIX or PMSF (Fig. 2A). When PTPN2 was incubated with various concentrations of PTP inhibitor XIX, proteolysis of PTPN2 by trypsin was decreased by PTP inhibitor XIX in a dose-dependent manner (Fig. 2B). In addition, PTP inhibitor XIX-mediated PTPN2 protection from proteolysis was also observed at different time points after trypsin treatment in a PTP inhibitor XIX dose-dependent manner (Fig. 2C). Collectively, the results suggest that PTP inhibitor XIX induces conformational changes in PTPN2 upon binding, thereby reducing protease susceptibility of PTPN2.

\section{Inhibitory effects of PTP inhibitor XIX on PTPN2-regulated STAT3 activity in mammalian cells}

We next measured the effect of PTP inhibitor XIX on PTPN2 expressed in mammalian cells to confirm its effect on cell permeability and effective binding to PTPN2 in cells. We carried out cell viability assays to determine the non-cytotoxic concentrations prior to its use in human embryonic kidney 293 (HEK 293) cells. Cell viability was analyzed by the ability of the cells to metabolically reduce a tetrazolium salt to a formazan dye. As shown in Fig. 3A, PTP inhibitor XIX showed no apparent cytotoxic effects up to $1.5 \mu \mathrm{M}$.

HEK 293 cells were transfected with FLAG-tagged PTPN2 wild type (WT) or C216S, a catalytically inactive mutant of PTPN2, expression plasmids and then treated with PTP inhibitor XIX. Cell lysates from treated HEK 293 cells were immunoprecipitated with FLAG M2-agarose and then the PTPN2 phosphatase activities were measured using 3-O-methylfluorescein phosphate (OMFP) as a substrate. As shown in Fig. 3B, the PTPN2 activity was reduced by the inhibitor in a dose-dependent manner, suggesting that PTP inhibitor XIX can inhibit PTPN2 in cells.

We next examined whether PTP inhibitor XIX inhibits dephosphorylation of PTPN2 substrates in mammalian cell. Since PTPN2 has been known to dephosphorylate signal transducer and activator of transcription 3 (STAT3) at Tyr-705 (15), we measured the STAT3 phosphorylation at Tyr-705 in IL-6-stimulated HEK 293 cells after treatment with PTP inhibitor XIX. HEK 293 cells transfected with FLAG-tagged PTPN2 WT or C216S plasmids were treated with PTP inhibitor XIX. After stimulation with IL-6, phosphorylation levels of STAT3 at Tyr-705 and total STAT3 protein levels were measured by immunoblotting analysis. As shown in Fig. 3C, PTPN2-mediated dephosphorylation of STAT3 at Tyr-705 by 
Table 1. Inhibitory effects of PTP inhibitor XIX on PTPs. Recombinant PTPs were incubated with 0,5 , and $10 \mu \mathrm{M}$ of PTP inhibitor XIX at $37^{\circ} \mathrm{C}$ for 30 min. IC 50 values of PTP activity were calculated by Prism 3.0. This experiment was performed as described in materials and methods. The experiments were performed in triplicates

\begin{tabular}{|c|c|c|c|}
\hline $\begin{array}{l}\text { Protein tyrosine } \\
\text { phosphatase }\end{array}$ & Classification & $\mathrm{IC}_{50}(\mu \mathrm{M})$ (using OMFP as a substrate) & References \\
\hline PTPN2 & NRPTPS & $0.95 \pm 0.05$ & This study \\
\hline CD45 & RPTPs & $\begin{array}{l}0.86 \pm 0.03^{*} \\
0.2 \mu \mathrm{M} \text { using } \mathrm{pNPP} \text { as a substrate }{ }^{* *} \\
3.8 \mu \mathrm{M} \text { using Ick505 peptide as a substrate** }\end{array}$ & $\begin{array}{l}\text { This study } \\
\text { (9) } \\
\text { (9) }\end{array}$ \\
\hline PTEN & PTENs & $\begin{array}{l}1.78 \pm 0.34^{*} \\
2 \mu \mathrm{M} \text { using pNPP as substrate } * *\end{array}$ & $\begin{array}{l}\text { This study } \\
\text { (10) }\end{array}$ \\
\hline DUSP3 & Atypical DUSPs & $>50$ & This study \\
\hline DUSP18 & Atypical DUSPs & $>50$ & This study \\
\hline DUSP23 & Atypical DUSPs & $>50$ & This study \\
\hline Cdc25B & Class III Cys-based & $>50$ & This study \\
\hline DUSP8 & MKPs & $>50$ & This study \\
\hline $\mathrm{SSH} 3$ & Slingshots & $>50$ & This study \\
\hline Laforin & RPTPs & $>100$ & This study \\
\hline
\end{tabular}

*The values were obtained by this study. ${ }^{*}$ The values were obtained from the experimental conditions that were different from this study.

its phosphatase activity was inhibited by PTP inhibitor XIX. Taken together, these results indicate that PTP inhibitor XIX effectively enhances STAT3 phosphorylation at Tyr-705 by inhibiting PTPN2 activity.

Many PTP inhibitors regulate their target PTPs by binding to their active sites that are shallow in general, suggesting that it may not be easy to develop highly selective PTP inhibitor derived from active site conformation. However, most known PTP inhibitors still show some selectivity towards PTPs, suggesting that the microenvironments of PTP active sites are different from one another. In addition, the PTP inhibitor selectivity may provide useful structural information around active sites of target PTPs that are not available from present protein structure databases. Since PTEN, CD45, and PTPN2 fall into different classes of PTPs but still are targets of PTP inhibitor XIX as shown in Table 1, it suggests that their conformation in active sites are similar and PTP inhibitor selectivity analysis might provide useful information for novel PTP classification.

PTPN2 enhances chronic myeloid leukemia by activating STAT5A, a member of STAT family or $\beta$-catenin pathway (16), and is associated with Crohn's disease (17). In addition, PTPN2 is involved in the risk of Behçet's disease in a Chinese Han population (18). Furthermore, PTP inhibitor XIX regulates PTEN and CD45 by binding to their catalytic sites. PTEN is associated with neutropenia disease and type II diabetes (11, 12), whereas CD45 is related to some autoimmune disorders and organ graft rejection (9). Since PTP inhibitor XIX binds and inhibits these PTPs, this inhibitor might act as a multiphosphatase inhibitor if used in vivo. Therefore, it is important to investigate how this multiphosphatase inhibitory effect leads to cell fate in those diseases.

\section{MATERIALS AND METHODS}

\section{Cell culture and transfection}

HEK 293 cells were maintained in Dulbecco's modified Eagle's medium supplemented with $10 \%$ fetal bovine serum (FBS; Invitrogen, Carlsbad, CA, USA) and 1\% penicillin/ streptomycin (Life Technologies, Grand Island, NY, USA) in the presence of $5 \% \mathrm{CO}_{2}$. For transfection, cells were seeded in $60 \mathrm{~mm}$ culture plate before the day of transfection and transfected with DNA using polyethylenimine (Polyscience Inc., Warrington, PA, USA).

\section{Antibodies and reagents}

Monoclonal anti-FLAG M2 agarose beads, anti-FLAG M2 antibody, anti- $\alpha$-tubulin antibody, PTP inhibitor XIX, and OMFP were purchased from Sigma-Aldrich (St.Louis, MO, USA). Anti-phospho-STAT3 (Tyr-705) and anti-His antibodies were from Cell Signaling Technology (Danvers, MA, USA). Trypsin was from Thermo Fisher Scientific (Waltham, MA, USA).

\section{PTPN2 WT and C216S plasmid construction}

His-tagged PTPs were constructed in pET28a (+) plasmid (Novagen, Darmstadt, Germany) for protein expression in Escherichia coli (E.coli). FLAG-tagged PTPN2 WT was constructed in pcDNA3.1 plasmid (Invitrogen). FLAG-tagged PTPN2 C216S phosphatase activity defective mutant was generated by site-directed mutagenesis using QuickChange II Site-Directed Mutagenesis Kit (Agilent Technologies, Santa 
PTP inhibitor XIX as a multiphosphatase inhibitor Hien Thi Thu Le, et al.

A

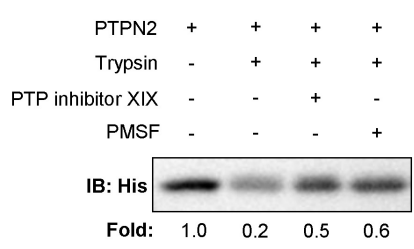

B

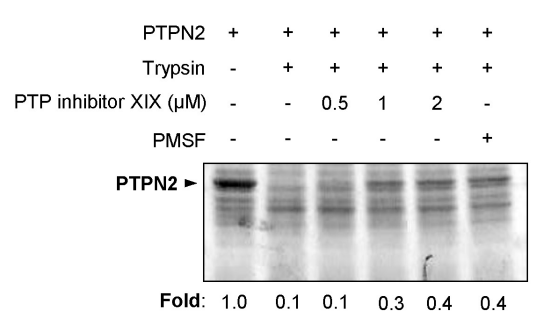

C

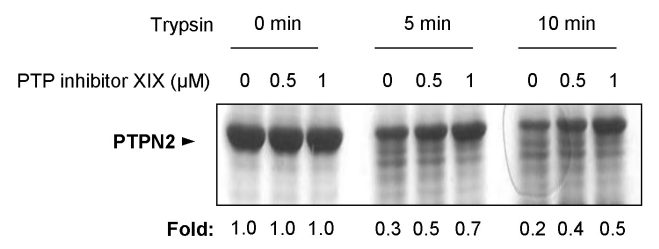

Fig. 2. Protective effect of PTP inhibitor XIX on PTPN2 proteolysis. (A) Purified PTPN2 was pretreated with PMSF $(1 \mu \mathrm{M})$ or PTP inhibitor XIX $(1 \mu \mathrm{M})$ for $20 \mathrm{~min}$. And then, the samples were incubated with trypsin on ice for $10 \mathrm{~min}$. The reactions were stopped with SDS sample buffer and were subjected to immunoblotting analysis. The expression of PTPN2 was detected with the anti-His antibody. The protein levels were measure using LabWorks software. IB, immunoblot. (B) After purified PTPN2 was pretreated with PMSF or different doses of PTP inhibitor XIX (0.5, 1 , and $2 \mu \mathrm{M}$ ) for $20 \mathrm{~min}$, the samples were incubated with trypsin on ice for $20 \mathrm{~min}$. Samples were run on $15 \%$ SDS gel and stained with Coomassie brilliant blue. The full length of PTPN2 levels were quantified using LabWorks software and represented as relative values compared to untreated PTPN2 group. (C) Purified PTPN2 $(100 \mu \mathrm{M})$ was incubated in the presence or absence of PTP inhibitor XIX $(0.5$ and $1 \mu \mathrm{M})$ for 20 min with PTPN2/trypsin (mol/mol) ratio 100:1. Reactions were terminated after 0,5 , or 10 min with SDS sample buffer. Samples were separated by $15 \%$ SDS gel and stained with Coomassie brilliant blue. The full length of PTPN2 levels were quantified using LabWorks software and represented as relative values compared to untreated PTPN2 group.

Clara, CA, USA). The complementary specific oligonucleotides used in the mutagenesis are as below; sense, 5'-CAATG CCTGCACTACTGTGGATCACCGCAGG-3'; antisense, 5'-CCT GCGGTGATCCACAGTAGTGCAGGCATTG-3'.

\section{Purification of $6 \mathrm{X}$ His tagged protein}

PTP expression plasmids constructed in pET28a $(+)$ were transformed into BL21 (DE3)-RIL E.coli. Bacteria were induced
A

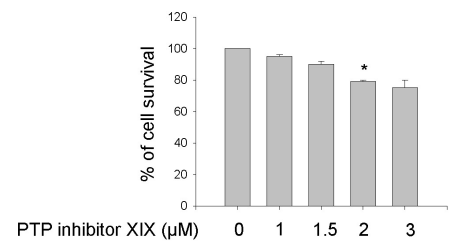

B

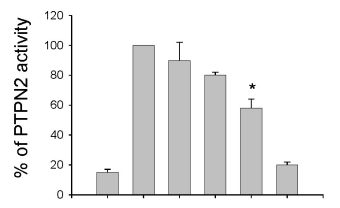

FLAG-PTPN2 WT -++++

FLAG-PTPN2 C216S - - - - - +

PTP inhibitor XIX $(\mu \mathrm{M}) \quad-\quad-\quad 0.5 \quad 1 \quad 1.5 \quad-$

IB: FLAG $-(--$

C

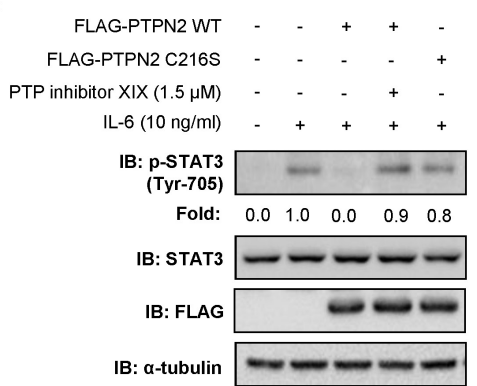

Fig. 3. Inhibitory effect of PTP inhibitor XIX on PTPN2 expressed in mammalian cells. (A) HEK 293 cells were seeded in 12-well plates. After overnight incubation, cells were treated with PTP inhibitor XIX $(1,1.5,2$, and $3 \mu \mathrm{M})$ for $6 \mathrm{~h}$. Cell viability assay were measured using EZ-Cytox cell viability assay kit. The results represent the mean \pm SEM from three independent experiments. $* \mathrm{P}<0.05$ relative to untreated group (Student's t-test). (B) HEK 293 cells were transfected with $1 \mu \mathrm{g}$ FLAG-tagged expression plasmids. After transfection, HEK 293 cells were treated with various concentrations of PTP inhibitor XIX $(0.5,1$, and $1.5 \mu \mathrm{M})$ for 6 h. Treated HEK 293 cells were lysed and cleared cell lysates were mixed with FLAG M2-agarose for immunoprecipitation as described in materials and methods. The immunoprecipitates were washed with PTP lysis buffer three times and their phosphatase activities were measured. The expression levels of PTPN2 were measured using immunoblotting analysis. The results represent the mean \pm SEM from three independent experiments. ${ }^{*} \mathrm{P}<0.05$ relative to FLAG-PTPN2 WT group (Student's t-test). (C) HEK 293 cells were transfected with FLAG-tagged expression plasmids. The transfected cells were treated with PTP inhibitor XIX $(1.5 \mu \mathrm{M})$ for $6 \mathrm{~h}$ and then stimulated with IL-6 (10 ng/ml) during $30 \mathrm{~min}$. Total cell lysates were prepared and subjected to immunoblotting analysis using appropriate antibodies. Protein levels were measured using LabWorks software. The expression of each group was compared to that IL-6-stimulated group.

with $1 \mathrm{mM}$ isopropyl $\beta$-D-1-thiogalactopyranoside (IPTG) at $37^{\circ} \mathrm{C}$ for $3 \mathrm{~h}$. Cells were harvested and then lysed by sonication in $50 \mathrm{mM}$ Tris- $\mathrm{HCl}$ (pH 6.8), $300 \mathrm{mM} \mathrm{NaCl}, 20 \mathrm{mM}$ 
imidazole, 1\% IGEPAL CA-630, and 2 mM PMSF. The lysates were centrifuged at $12,000 \mathrm{rpm}$ for $30 \mathrm{~min}$ at $4^{\circ} \mathrm{C}$. The supernatant was applied to a column of Ni-NTA resin (PEPTRON, Daejeon, Korea) by gravity flow. The resin was washed with $20 \mathrm{mM}$ Tris- $\mathrm{HCl}(\mathrm{pH} 8.0), 300 \mathrm{mM} \mathrm{NaCl}$, and 20 $\mathrm{mM}$ imidazole and then eluted with $20 \mathrm{mM}$ Tris- $\mathrm{HCl}(\mathrm{pH} 8.0)$, $300 \mathrm{mM} \mathrm{NaCl}$, and $250 \mathrm{mM}$ imidazole. The eluted proteins were dialyzed overnight against $20 \mathrm{mM}$ Tris- $\mathrm{HCl}, 150 \mathrm{mM}$ $\mathrm{NaCl}, 20 \%$ glycerol, and $0.5 \mathrm{mM}$ PMSF and stored at $-80^{\circ} \mathrm{C}$ before use.

\section{Measurement of phosphatase activity in vitro}

The activity of phosphatases was measured using OMFP as a substrate based on the method described previously (19). PTP inhibitor XIX and OMFP were solubilized in $\mathrm{H}_{2} \mathrm{O}$ and dimethyl sulfoxide (DMSO), respectively, and all reactions were performed at a final concentration of $1 \%$ DMSO. The reaction $(150 \mu \mathrm{l})$ was performed in reaction buffer $[30 \mathrm{mM}$ Tris- $\mathrm{HCl}(\mathrm{pH} 7.0), 75 \mathrm{mM} \mathrm{NaCl}, 1 \mathrm{mM}$ ethylenediaminetetraacetic acid (EDTA), $0.4 \mathrm{mM}$ dithiothreitol (DTT), $0.132 \%$ bovine serum albumin (BSA), $100 \mathrm{nM}$ of PTPs, and $100 \mu \mathrm{M}$ OMFP]. The reaction was started with the addition of OMFP and proceeded during incubation for $30 \mathrm{~min}$ at $37^{\circ} \mathrm{C}$. After incubation, the fluorescence was measured at $495 \mathrm{~nm}$ (excitation) and $535 \mathrm{~nm}$ (emission) using a Synergy $\mathrm{H} 1$ Microplate Reader (BioTek Instruments, Inc., Winooski, VT, USA). $I C_{50}$ was determined using the curve fitting program Prism 3.0 (GraphPad Software Inc., La Jolla, CA, USA).

For in vitro phosphatase assays with PTPN2 expressed in HEK 293 cells, cells were transfected with FLAG-tagged PTPN2 WT or C216S plasmids for $42 \mathrm{~h}$, and then treated with PTP inhibitor XIX for $6 \mathrm{~h}$. Treated cells were lysed in PTP lysis buffer $(150 \mathrm{mM} \mathrm{NaCl}, 20 \mathrm{mM}$ Tris-HCl $(\mathrm{pH}$ 8.0), 0.5\% IGEPAL CA-630 (NP-40), $0.5 \%$ Triton X-100, 1 mM EDTA, 1\% glycerol, and $2 \mathrm{mM}$ PMSF). Cleared cell lysates were mixed with FLAG M2-agarose and incubated for $3 \mathrm{~h}$ at $4^{\circ} \mathrm{C}$ using a rotation device. After incubation, FLAG M2-agarose was washed 3 times with PTP lysis buffer and OMFP was used as substrate. The phosphatase-mediated hydrolysis of OMFP was measured using the aforementioned Synergy H1 Microplate Reader.

\section{Kinetic analysis}

The inhibition constant $\left(\mathrm{K}_{\mathrm{i}}\right)$ of PTPN2 phosphatase was calculated using Lineweaver-Burk plots. The initial rates were measured at various OMFP concentrations for each fixed concentration of PTP inhibitor XIX and the slopes showed the competitive inhibition pattern. The $K_{i}$ value was obtained from the below equation of competitive inhibition (20). All experiments were performed in triplicates and repeated independently at least three times.

$$
\frac{1}{\mathrm{~V}}=\mathrm{K}_{\mathrm{m}}\left(1+\frac{[\mathrm{I}]}{\mathrm{K}_{\mathrm{i}}}\right) \times \frac{1}{\mathrm{~V}_{\max } \times[\mathrm{S}]}+\frac{1}{\mathrm{~V}_{\max }}
$$

$\mathrm{V}$, velocity; I, inhibitor; $\mathrm{S}$, substrate; $\mathrm{V}_{\max }$, maximal velocity; $K_{m}$, Michaelis constant; $K_{i}$, inhibition constant

\section{DARTS assays}

Purified PTPN2 was incubated with PMSF $(1 \mu \mathrm{M})$ or PTP inhibitor XIX $(1 \mu \mathrm{M})$ for $20 \mathrm{~min}$, and then further incubated in the presence of trypsin on ice for 10 or $20 \mathrm{~min}$ in the reaction buffer $[100 \mathrm{mM}$ Tris-Cl $(\mathrm{pH}$ 8.5), $1 \mathrm{mM} \mathrm{HCl}$, and $20 \mathrm{mM}$ $\mathrm{CaCl}_{2}$ in phosphate-buffered saline (PBS) (pH 7.4)]. The PTPN2/trypsin (mol/mol) ratio was 100:1. Reaction was terminated by the addition of stop solution [500 mM EDTA (pH 8.0), and $200 \mathrm{mM}$ PMSF in $5 \mathrm{X}$ sodium dodecyl sulfate (SDS) sample buffer]. Samples were subjected to SDS-polyacrylamide gels and immunoblotting analysis with an anti-His antibody for the detection of PTPN2.

For detection with Coomassie brilliant blue, samples were run on $15 \%$ SDS-polyacrylamide gels. The gels were fixed in fixing solution ( $40 \%$ methanol, and $10 \%$ acetic acid) for $1 \mathrm{~h}$ at room temperature. After staining for $30 \mathrm{~min}$ in Coomassie brilliant blue (1.25\% Coomassie brilliant blue, $22.5 \%$ methanol, and $0.5 \%$ acetic acid), gels were incubated overnight with destaining solution $(0.5 \%$ methanol and $0.8 \%$ acetic acid).

For the detection of PTPN2 cleavage at the different times, PTP inhibitor XIX $(0.5$ and $1 \mu \mathrm{M})$ was incubated with purified PTPN2 $(100 \mu \mathrm{M})$ for $20 \mathrm{~min}$ on ice. The PTPN2/trypsin ratio was 100:1. Reaction was terminated after 0,5 , and $10 \mathrm{~min}$ by adding the stop solution. Samples were performed on $15 \%$ SDS-polyacrylamide gels and stained with Coomassie brilliant blue.

\section{Cell viability assays}

HEK 293 cells were seeded in 12-well plates $\left(1.5 \times 10^{6}\right.$ cells/well). After incubation overnight, cells were treated with PTP inhibitor XIX for $6 \mathrm{~h}$. Cell viability was analyzed using the EZ-Cytox cell viability assay kit (Daeil Lab, Seoul, Korea). EZ-Cytox solution that contains a water soluble tetrazolium salt was added to cells and then incubated for $1 \mathrm{~h}$ at $37^{\circ} \mathrm{C}$. The absorbance was measured at $450 \mathrm{~nm}$ (absorbance for viable cells) and $650 \mathrm{~nm}$ (reference absorbance) with the Synergy $\mathrm{H} 1$ Microplate Reader.

\section{Immunoblotting analysis}

After HEK 293 cells were transfected with FLAG-tagged PTPN2 WT or catalytically inactive C216S mutant expression plasmids for $48 \mathrm{~h}$, cells were washed twice with PBS and lysed in PTP lysis buffer. Lysed cells were centrifuged at 13,000 rpm for 30 $\min$ at $4^{\circ} \mathrm{C}$ and the supernatants were transferred to a new tube. The protein concentration was determined by protein assay reagent (Bio-Rad, Hercules, CA, USA) according to the manufacturer's instruction. Samples were boiled with $5 \mathrm{X}$ SDS sample buffer (12 mM Tris- $\mathrm{HCl}(\mathrm{pH}$ 6.8), 0.4\% SDS, 5\% glycerol, $1 \% \quad \beta$-mercaptoethanol, and $0.02 \%$ bromophenol blue) and boiled at $100^{\circ} \mathrm{C}$ for $5 \mathrm{~min}$. Samples were run on $10 \%$ SDS-polyacrylamide gels and transferred to nitrocellulose 
membranes. The membranes were blocked with $5 \%$ skim milk for $1 \mathrm{~h}$ and incubated with appropriate primary antibody at $4^{\circ} \mathrm{C}$ overnight. Blots were washed four times with Tween 20/Tris-buffered saline and incubated with a secondary antibody. The protein bands were visualized using enhanced chemiluminescence $(\mathrm{ECL})$ immunoblotting detection reagent (Pierce, Rockford, IL, USA). Protein levels were quantified by scanning and analyzing the immunoblots using LabWorks software (UVP Inc., Upland, CA, USA).

\section{Immunoblotting analysis for phosphorylation of STAT3 Tyr-705}

HEK 293 cells were transfected with FLAG-tagged PTPN2 WT or C216S plasmids. After $42 \mathrm{~h}$, transfected cells were treated with PTP inhibitor XIX $(1.5 \mu \mathrm{M})$ for $6 \mathrm{~h}$, and then stimulated with IL-6 $(10 \mathrm{ng} / \mathrm{ml})$ for $30 \mathrm{~min}$. Cells were lysed in PTP lysis buffer and subjected to immunoblotting analysis. Samples were boiled at $100^{\circ} \mathrm{C}$ for $5 \mathrm{~min}$, run on SDS-polyacrylamide gels followed by immunoblotting analysis with specific antibodies. The protein bands were visualized using ECL.

\section{Statistical analysis}

The data are expressed as mean \pm standard error of the mean (SEM). The data were assessed by Student's t-test using Prism 3.0 software and $* \mathrm{P}<0.05$ was considered statistically significant.

\section{ACKNOWLEDGEMENTS}

This research was supported by the National Research Foundation of Korea (NRF) grant funded by the Ministry of Science, ICT \& Future Planning (NRF-2015R1A2A2A1100 1446 and 2015R1A5A1008958).

\section{CONFLICTS OF INTEREST}

The authors have no conflicting financial interests.

\section{REFERENCES}

1. Hunter T (2000) Signaling-2000 and Beyond. Cell 100, 113-127

2. Ciesla J, Fraczyk T and Rode W (2011) Phosphorylation of basic amino acid residues in proteins: important but easily missed. Acta Biochim Pol 58, 137-148

3. Barford D, Das AK and Egloff MP (1998) The structure and mechanism of protein phosphatases: insights into catalysis and regulation. Annu Rev Biophys Biomol Struct 27, 133-164

4. Alonso A, Sasin J, Bottini N et al (2004) Protein tyrosine phosphatases in the human genome. Cell 117, 699-711
5. Bononi A, Agnoletto C, De Marchi E et al (2011) Protein kinases and phosphatases in the control of cell fate. Enzyme Res 2011, 329098

6. Heneberg P (2009) Use of protein tyrosine phosphatase inhibitors as promising targeted therapeutic drugs. Curr Med Chem 16, 706-733

7. Zhang ZY (2002) Protein tyrosine phosphatases: structure and function, substrate specificity, and inhibitor development. Annu Rev Pharmacol Toxicol 42, 209-234

8. Scott LM, Lawrence HR, Sebti SM, Lawrence NJ and Wu J (2010) Targeting protein tyrosine phosphatases for anticancer drug discovery. Curr Pharm Des 16, 1843-1862

9. Urbanek RA, Suchard SJ, Steelman GB et al (2001) Potent reversible inhibitors of the protein tyrosine phosphatase CD45. J Med Chem 44, 1777-1793

10. Spinelli L, Lindsay YE and Leslie NR (2015) PTEN inhibitors: an evaluation of current compounds. Adv Biol Regul 57, 102-111

11. Li Y, Jia Y, Pichavant $M$ et al (2009) Targeted deletion of tumor suppressor PTEN augments neutrophil function and enhances host defense in neutropenia-associated pneumonia. Blood 113, 4930-4941

12. Rosivatz E, Matthews JG, McDonald NQ et al (2006) A small molecule inhibitor for phosphatase and tensin homologue deleted on chromosome 10 (PTEN). ACS Chem Biol 1, 780-790

13. Chang J, Kim Y and Kwon HJ (2016) Advances in identification and validation of protein targets of natural products without chemical modification. Nat Prod Rep 33, 719-730

14. García-Carreño FL (1992) Protease inhibition in theory and practice. Biotechnology Education 3, 145-150

15. Lee H, Morales LD, Slaga TJ and Kim DJ (2015) Activation of T-cell protein-tyrosine phosphatase suppresses keratinocyte survival and proliferation following UVB irradiation. J Biol Chem 290, 13-24

16. Kok CH, Leclercq T, Watkins DB et al (2014) Elevated PTPN2 expression is associated with inferior molecular response in de-novo chronic myeloid leukaemia patients. Leukemia 28, 702-705

17. Yu W, Hegarty JP, Berg A et al (2012) PTPN2 is associated with Crohn's disease and its expression is regulated by NKX2-3. Dis Markets 32, 83-91

18. Wu Z, Chen H, Sun F et al (2014) PTPN2 rs1893217 single-nucleotide polymorphism is associated with risk of Behcet's disease in a Chinese Han population. Clin Exp Rheumatol 32, S20-26

19. Tierno MB, Johnston PA, Foster C et al (2007) Development and optimization of high-throughput in vitro protein phosphatase screening assays. Nat Protoc 2, 1134-1144

20. Shi Z, Tabassum S, Jiang W et al (2007) Identification of a potent inhibitor of human dual-specific phosphatase, VHR, from computer-aided and NMR-based screening to cellular effects. Chembiochem 8, 2092-2099 